\title{
FLORA DA BAHIA: LEGUMINOSAE - MACROPTILIUM (PAPILIONOIDEAE: PHASEOLEAE)
}

\author{
Carolina Lima Ribeiro ${ }^{\mathbf{1}}$; Luciano Paganucci de Queiroz $^{\mathbf{2}}$ e Cristiane Snak ${ }^{\mathbf{3}}$ \\ 1. Bolsista PIBIC/FAPESB, Graduando em Ciências Biológicas, Universidade Estadual de Feira de Santana, email: \\ carolima.clr@gmail.com \\ 2. Orientador, Departamento de Ciências Biológicas, Universidade Estadual de Feira de Santana, email: \\ luciano.paganucci@gmail.com \\ 3. Coorientadora, Departamento de Ciências Biológicas, Universidade Estadual de Feira de Santana, email: \\ cristianesnak@gmail.com
}

PALAVRAS-CHAVE: Phaseolinae; Phaseolus s.1; taxonomia.

\section{INTRODUÇÃO}

Leguminosae é a terceira maior família de Angiospermas, possuindo mais de 19.500 espécies e 770 gêneros, com uma ampla distribuição geográfica, ocorrendo em todos os continentes com exceção da Antártica (Schrire et al. 2005; Lewis et al. 2005, 2013; LPWG 2013). Papilionoideae é a mais diversa das seis subfamílias de Leguminosae, compreendendo cerca de 14.000 espécies, 503 gêneros e 29 tribos (Lewis et al. 2005; Queiroz et al. 2015; LPWG 2017).

Dentre as tribos de Papilionoideae, Phaseoleae possui o maior número de gêneros e está distribuída principalmente nas regiões tropicais e subtropicais (Lackey 1981). A subtribo Phaseolinae compreende 27 gêneros e cerca de 340 espécies, com as seguintes características morfológicas: hábito volúvel, folhas trifolioladas, estilete barbado e sementes com epihilo (Lackey 1981; Lavin \& Delgado-Salinas 1990; Delgado-Salinas et al. 2011).

Macroptilium (Benth.) Urb. é um gênero da subtribo Phaseolinae, monofilético (Espert et al. 2007) composto por 20 espécies distribuídas apenas na América, das quais 12 ocorrem no Brasil (Moura 2010; Delgado-Salinas et al. 2011). O gênero possui grande importância econômica e suas espécies são utilizadas como plantas forrageiras e na recuperação de áreas degradadas por sua eficiência na fixação de nitrogênio (Freitas et al. 2011).

Algumas revisões taxonômicas do gênero foram feitas por Beyra \& Reyes (2005) em Cuba, Drewes (1995) na Argentina e Barbosa-Fevereiro (1987) no Brasil. Entretanto, muitos espécimes depositados nos herbários não condizem com nenhuma das espécies, de fato, descritas até então. Considerando a diversidade de espécie de Macroptilium na Bahia, é de extrema relevância a revisão do gênero no estado para uma delimitação morfológica das espécies e compreensão da sua taxonomia. Desta forma, esse trabalho teve como objetivo realizar um estudo taxonômico do gênero Macroptilium na Bahia, contribuindo para o conhecimento da diversidade botânica do Estado.

\section{METODOLOGIA}

Foram realizadas visitas aos herbários da Bahia [CEPEC, HUEFS, HURB - acrônimos de acordo com Thiers (2017)] e revisões bibliográficas de obras que abordaram o gênero. Posteriormente foram realizadas expedições para coleta de espécimes nas regiões do estado que tiveram maior diversidade do gênero. Parte do material coletado foi fixado em etanol $70 \%$, para posterior aferição das medidas das peças florais. Folhas foram desidratadas em sílica gel para estudos futuros. As amostras foram depositadas no Herbário da Universidade Estadual de Feira de Santana (HUEFS) e duplicatas enviadas para outros herbários do Estado.

As descrições morfológicas foram feitas a partir das exsicatas e materiais coletados, consultando os tipos nomenclaturais e as obras príncipes das espécies da Bahia e seus sinônimos. As medidas foram tomadas em estruturas adultas. O trabalho contém chave de 
identificação, descrições taxonômicas, comentários taxonômicos e de distribuição geográfica, dados de floração e frutificação, mapas de distribuição, ilustrações e prancha de fotos.

\section{RESULTADOS}

O tratamento taxonômico contou com a análise de mais de 400 materiais de herbário, dentre eles aproximadamente 50 foram corrigidas ou identificadas para as espécies já descritas e nove espécimes não correspondiam com as espécies descritas para o gênero, os quais estão em estudo para a descrição de uma espécie nova para o gênero.

Macroptilium (Benth.) Urb.

Erva ou subarbusto, ramos eretos, prostrados ou volúveis. Estípulas persistentes. Folhas pinadas, trifolioladas; folíolos laterais, geralmente assimétricos e terminais simétrico. Inflorescência pseudoracemosa, axilar; brácteas de primeira ordem formando dois tufos na base do pedúnculo ou formando um anel de brácteas estipitado, persistentes; brácteas de segunda ordem na base dos pedicelos florais, caducas; bractéolas na base do cálice, caducas. Flores assimétricas; cálice 5-laciniado, simétrico; pétalas atropurpúreas, vermelhas, alaranjadas, roxas ou esverdeadas, unguiculadas, estandarte reflexo, alas mais longas que o estandarte, pétalas da carena com rostro em forma de gancho rotacionado para direita, com exceção de uma espécie que apresenta rostro cocleado (M. cochleatum); androceu com 10 estames, diadelfo, anteras dorsifixas; gineceu com ovário séssil, estilete barbado, estigma terminal, capitado. Legume, linear ou falcado, ápice acuminado, deiscência elástica. Sementes, oblongas ou subelipsoides, ligeiramente compressas, ápice e base arredondadas; hilo oblongo, lateral.

Macroptilium é um gênero que ocorre apenas na América, possuindo dois centros de diversidade, o México na América do Norte, e o Brasil e o Paraguai, na América do Sul (Barbosa-Fevereiro, 1987). No Brasil, ocorrem em regiões de Caatinga, Cerrado, Mata Atlântica, ambientes costeiros, campo ou restinga (Barbosa-Fevereiro, 1987). As espécies são geralmente herbáceas ou subarbustivas, tendo como característica diagnostica a posição das alas incomum, sendo elas maiores que o estandarte. No Brasil ocorrem 14 espécies, com ocorrência em todas as regiões, sendo duas endêmicas (BFG 2015).

Foram registradas dez espécies para a Bahia: M. atropurpureum (Moc. \& Sessé ex DC.) Urb., M. bracteatum (Nees \& Mart.) Maréchal \& Baudet, M. cochleatum (A. Delgado \& G.P. Lewis), M. erythroloma (Mart. ex Benth), M. gracile (Poepp. ex Benth.), M. lathyroides (L.) Urb., M. martii (Benth.) Maréchal \& Baudet, M. panduratum (Benth.) Maréchal \& Baudet e M. sabaraense (Hoehne) V.P. Barbosa ex G.P. Lewis e uma nova espécie que está sendo descrita.

Nas espécies encontradas na Bahia, foi observado que grande parte delas são herbáceas, apenas $M$. lathyroides e M. bracteatum são subarbustivas, as espécies possuem uma ampla variação em tamanho e forma dos folíolos, mesmo assim apresentam características determinantes para distinção de cada espécie.

Três espécies possuem cálice campanulado, frutos menores que $2 \mathrm{~cm}$ de comprimento com menos de 5 sementes: (I) M. cochleatum, que se diferencia principalmente por possuir flores com carena cocleada, sendo endêmica no Nordeste do Brasil (Delgado-Salinas \& Lewis 2008), na Bahia ocorre em Caatinga; (II) M. martii, que se diferencia por possuir folíolos vilosos a velutinos e legumes falcados e lanuginosos, ocorrendo apenas na região Nordeste no Brasil (BFG 2015), na Bahia ocorre em Caatinga e Cerrado; (III) M. sabaraense que possui legumes falcados com valvas compressas entre as sementes e sementes subelipsoides, com ocorrência no Nordeste, Centro-Oeste e Sudeste do Brasil (BFG 2015), na Bahia ocorre em Caatinga e Cerrado. 
As demais sete espécies possuem o cálice tubuloso a subtubuloso, frutos maiores que $3,5 \mathrm{~cm}$ de comprimento com mais de 6 sementes, dentre elas apenas a $M$. lathyroides não possui brácteas de primeira ordem, tendo como característica principal os ramos pubescentes a glabrescentes e os folíolos glabrescentes a glabros, ocorre em todas as regiões do Brasil, possui uma ampla distribuição no estado, frequente em ambientes antropizados.

As seis espécies restantes possuem brácteas de segunda ordem, podendo estar dispostas na base do pedúnculo ou elevadas em um estípite no pedúnculo. As espécies que possuem brácteas de segunda ordem na base são: (I) M. gracile, que possui folíolos ovados a lanceolados, geralmente lobados na porção inferior, broquidodromos, é endêmica do Brasil, com distribuição no Norte, Nordeste, Centro-Oeste e Sudeste (BFG 2015), na Bahia ocorre em Caatinga; (II) M. panduratum (Fig. 1A), caracterizado por possuir folíolos crenados e estandarte assimétrico, distribuída no Nordeste e Sudeste do Brasil (BFG 2015), na Bahia ocorre em Caatinga.

As quatro espécies que possuem pedúnculo estipitado são: (I) M. atropupureum com brácteas de primeira ordem curtas, sem formar anel completo, brácteas de segunda ordem e bractéolas sempre mais curtas que o cálice e flores atropurpúreas, distribuído por todo o Brasil (BFG 2015), na Bahia é frequente na Caatinga e em ambientes costeiros; (II) $M$. bracteatum (Fig. 1B), com brácteas de primeira ordem longas, formando anel completo, com brácteas de segunda ordem mais longas que o cálice, flores vináceas, no Brasil ocorre no Nordeste, Centro-Oeste, Sudeste e Sul, é amplamente distribuído na Bahia, ocorrendo na Caatinga e no Cerrado, principalmente em ambientes antropizados; (III) M. erythroloma, com brácteas de primeira ordem lineares a assoveladas, geralmente formando anel completo, estandarte com papilas, flores alaranjadas e róseas, no Brasil tem ocorrência no Nordeste, Centro-Oeste, Sudeste e Sul (BFG 2015), na Bahia ocorre em área de Caatinga, no Nordeste; (IV) Macroptilium sp com brácteas de primeira ordem sem formar anel completo, geralmente formando dois tufos nas laterais, as bractéolas são menores que o cálice, mas apresenta o ápice da inflorescência congesto, estandarte sem papilas, flores brancas a esverdeadas, características que conjuntas, não são encontradas nas espécies já descritas, ocorrem no Nordeste da Bahia, em área de Caatinga

\section{CONCLUSÃO}

Este estudo contribuiu para o conhecimento do gênero Macroptilium no estado da Bahia. Foram reconhecidas para o estado dez espécies, que diferem principalmente quanto às inflorescências, flores e frutos. Antes eram descritas nove para o estado. A décima espécie encontrada, não condiz com nenhuma das espécies já descritas para o gênero, assim a espécie nova está sendo descrita. Ocorrem principalmente nas regiões Nordeste e Centro-Oeste da Bahia. Algumas são amplamente distribuídas geograficamente no estado, como Macroptilium bracteatum, $M$. lathyroides e $M$. martii, com baixa incidência de espécies em geral no Extremo Sul e no Extremo Oeste.
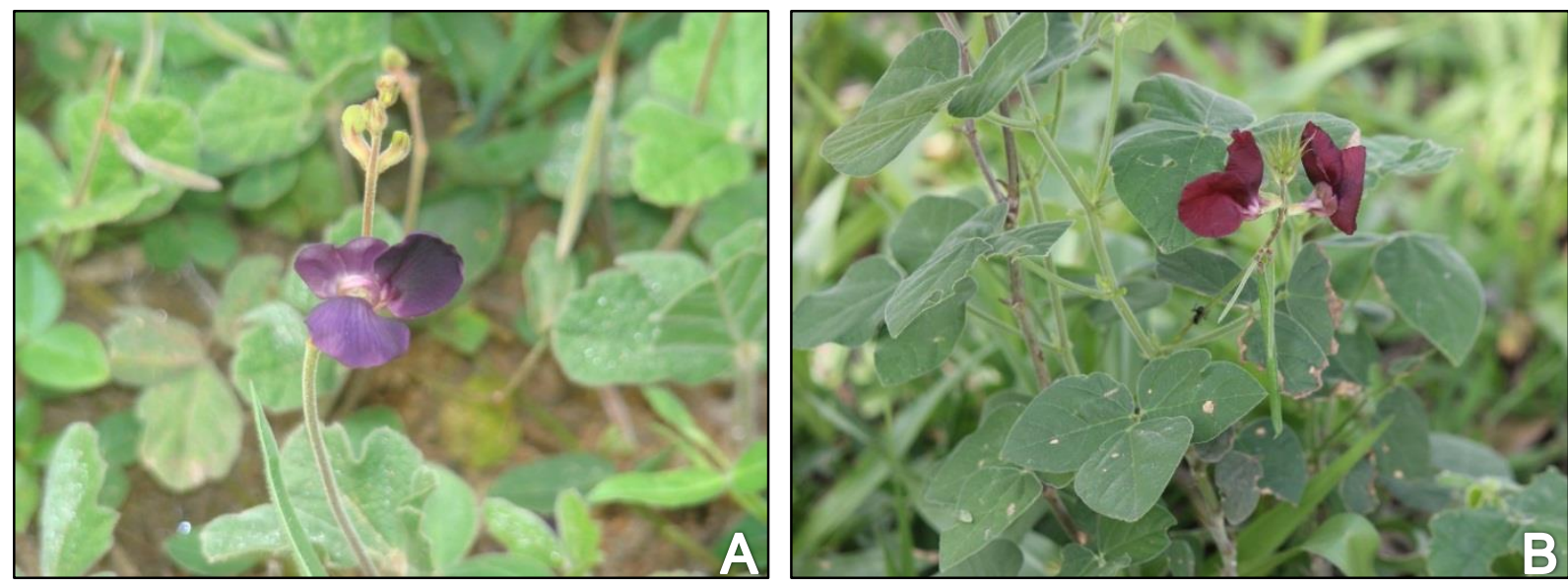

Figura 1. A. Macroptilium panduratum. B. M. bracteatum. Fotos por: C. L. Ribeiro 


\section{REFERÊNCIAS}

BARBOSA FEVEREIRO, V.P. 1987. Macroptilium (Bentham) Urban do Brasil (Leguminosae - Faboideae - Phaseoleae - Phaseolinae). Arch. Jard. Bot. Rio Janeiro 28, 109-180.

BEYRA, A. \& REYES, G. 2005. El género Macroptilium (Benth) Urb. (Leguminosae) en Cuba Anal. Jardin. Bot. Mad. 62: 181-190.

BFG (The Brazil Flora Group) 2015. Growing knowledge: an overview of Seed Plant knowledge in Brazil. Rodriguésia 66: 1085-1113.

DELGADO-SALINAS, A. \& LEWIS, G.P. 2008. A new species of Macroptilium (Benth.) Urban (Leguminosae: Papilionoideae: Phaselinae) From Northeastern Brazil. Kew Bull. 63: 151-154.

DREWES, S.I. 1995. Revisión de las especies argentinas del género Macroptilium (Benth.) Urban (Leguminosae-Phaseolinae). Facultad de Ciencias Exactas y Naturales. Universidad de Buenos Aires.

ESPERT, S. M., DREWES, S. I. \& BURGHARDT, A.D. 2007. Phylogeny of Macroptilium (Leguminosae): Morphological, biochemical and molecular evidence. Cladistics 23: 119129.

FREITAS, A.D.S.DE, SILVA, T.O.DA, MENEZES, R.S.C., SAMPAIO, E.V.DE S.B., ARAÚJO, E.R., FRAGA, V.DA S. 2011. Nodulação e fixação de nitrogênio por forrageiras da caatinga cultivadas em solos do semiárido paraibano. R. Bras. Zootec., Set vol.40, no.9, p.1856-1861. ISSN 1516-3598.

LACKEY, J.A. 1981. Phaseoleae. In: Polhill, R.M. \& Ravwn, P.H. [eds]. Adv. Legum. Systemat., part 1. Royal Botanic Gardens, Kew, pp. 301-327.

LAVIN, M. \& DELGADO-SALINAS, A. 1990. Pollen Brush of Papilionoideae (Leguminosae): morphological variation and systematic utility. Am. J. Bot. 77: 1294-1312.

LEWIS, G.P., SCHRIRE, B.D., MACKINDER, B.A. \& LOCK, M. [eds]. 2005. Legumes of the Word. Royals Botanic Gardens, Kew. 529 pp.

LEWIS, G.P., SCHRIRE, B.D., MACKINDER, B.A., RICO, L. \& CLARK, R. 2013. A 2013 linear sequence of legume genera set in a phylogenetic context: A tool for collections management and taxon sampling. S. Afr. J. Bot. 89: 76-84.

LPWG [Legume Phylogeny Working Group]. 2013. Legume phylogeny and classification in the 21st century: Progress, prospects and lessons for other species-rich clades. Taxon 62: 217248.

LPWG. 2017. Phylogeny and classification of the Leguminosae. Taxon 66: 44-77.

QUEIROZ, L.P., PASTORE, J.F.B., CARDOSO, D., SNAK, C., LIMA, A.L.C., GAGNON, E., VATANPARAST, M., HOLLAND, A.E., \& EGAN, A.E. 2015. A multilocus phylogenetic analysis reveals the monophyly of a recircumscribed papilionoid legume tribo Diocleae with well-supported generic relationships. Mol. Phylogenet. Evol. 90: 1-19.

SCHRIRE, B.D., LAVIN, M. \& LEWIS, G.P. 2005. Global distribution patterns of the Leguminosae: Insights from recent phylogenies. In: Friis, I. \& Balslev, H. [eds]. Plant devirsity and complexity patterns: Local, regional ano global dimensions. Biol. Skif. 55: 375422.

THIERS, B. [atualizado continuamente]. Index Herbariorum: A global directory of public herbaria and associated staff. New York Botanical Garden's Virtual Herbarium. Available from: http://sweetgum.nybg.org/ih/ (acesso: 03 de agosto de 2017). 